\title{
Validation of the Updated Korean Calcium Assessment Tool
}

\author{
Joowon Jin, Yunjung Lee, Yongsoon Park \\ Department of Food and Nutrition, Hanyang University, Seoul, Korea
}

\author{
Corresponding author \\ Yongsoon Park \\ Department of Food and Nutrition, Hanyang \\ University, 222 Wangsimni-ro, Seongdong-gu, \\ Seoul 04763, Korea \\ Tel: +82-2-2220-1205 \\ Fax: +82-2-2220-1856 \\ E-mail: yongsoon@hanyang.ac.kr
}

Received: October 27, 2021

Revised: November 22, 2021

Accepted: November 24, 2021
Copyright $@ 2021$ The Korean Society for Bone and Mineral Research

This is an Open Access article distributed under the terms of the Creative Commons Attribution Non-Commercial License (https://creativecommons.org/licenses/by-nc/4.0/) which permits unrestricted non-commercial use, distribution, and reproduction in any medium, provided the original work is properly cited.

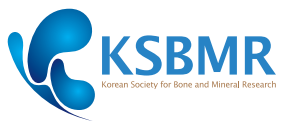

Background: We previously developed the Korean Calcium Assessment Tool (KCAT) for assessing the intake of calcium and vitamin D in Korean women. However, based on the Korea National Health and Nutrition Examination Survey (KNHANES) VI and VII (20132018), major food sources for calcium and vitamin D have changed, and the National Standard Food Composition database was updated. Therefore, the present study aimed to update the KCAT and validate the Updated KCAT. Methods: A total of 285 women aged $>19$ years were asked to complete questionnaires of the KCAT and the Updated KCAT. Results: Calcium intake did not differ significantly between the KCAT $(566 \pm 245$ $\mathrm{mg} /$ day) and the Updated KCAT $(569 \pm 248 \mathrm{mg} /$ day; $P=0.343)$. A correlation coefficient of 0.99 indicated a positive correlation on calcium intake between the KCAT and the Updated KCAT, with an almost perfect agreement by Cohen's $\mathrm{K}$ coefficients (0.95). Vitamin $D$ intake assessed by the Updated KCAT was significantly higher than that assessed by the KCAT, which was positively correlated with a moderate agreement measured by Cohen's $\mathrm{k}$ coefficients $(0.41)$. Conclusions: The present study demonstrated that the Updated KCAT was a valid tool for the rapid evaluation of calcium and vitamin D intake for Korean women.

Key Words: Calcium · Calcium, dietary · Diet surveys · Vitamin D

\section{INTRODUCTION}

Osteoporosis is characterized by decreased bone density with consequence increases in bone fragility and has become a serious health problem.[1] An osteoporosis prevalence of $32.6 \%$ has been reported in Korean adult women,[2] and older postmenopausal women are particularly affected by the disease.[3] The Korea National Health and Nutrition Examination Survey (KNHANES) indicated that the osteoporosis prevalence rate is 6 times higher in women than men and increases with age.[2]

Sufficient nutrition, particularly adequate intake of calcium plays an important role in prevention and treatment of osteoporosis.[4-6] However, only 27.4\% Korean women satisfied calcium intake up to the level of the dietary reference intakes for Koreans (KDRI).[7] Vitamin D is also an essential nutrient for bone health in terms of optimal calcium absorption,[8] but the intake is low at all ages in Korean compared with KDRI.[7]

Food frequency questionnaires (FFQ), 24-hr recall, and dietary records are used 
for the assessment of all the nutrient intakes, but it takes a long time to complete. Simple calcium questionnaires called the Calcium Calculator ${ }^{\mathrm{TM}}[9,10]$ is available to assess the calcium intake in a western country, where people's main source of calcium is dairy products. However, our previous study showed that Korean women consumed only $1 / 3$ of their calcium intake from dairy products, and vegetables were substantial source of calcium.[11] Dark green vegetables were a practical source of dietary calcium for Korean women, although calcium in vegetables has low bioavailability compared to the calcium in dairy products.[12,13] Thus, we previously developed the Korean Calcium Assessment Tool (KCAT) to assess the calcium and vitamin D intake for Korean women in 2013.[14] However, KNHANES VI and VII conducted during 2013 to 2018 showed that major food sources of calcium and vitamin $D$ have been changed. [15-20] In addition, the National Standard Food Composition Table was updated in 2020,[21] and Computer Aided Nutritional analysis Program (CAN-Pro; Korean Nutrition Society, Seoul, Korea) was upgraded from version 4.0 to version 5.0 in 2021. Therefore, major food sources and amount of calcium and vitamin D in the KCAT are needed to update, and the Updated KCAT is needed to validate by comparing with the original KCAT.

\section{METHODS}

\section{Participants}

The study was conducted in accordance with the Declaration of Helsinki, and all procedures involving human participants were approved by the Institutional Review Board (IRB) of Hanyang University (HYUIRB-202103-021). Informed consent were obtained from all participants. Korean women with $>19$ years old were recruited and excluded if they were pregnant or breastfeeding. Participants were recruited Hanyang University, Seoul, Korea. Two hundred and eighty-5 Korean women completed both the KCAT and Updated KCAT were included in the analysis.

\section{Assessment of dietary calcium and vitamin D intake}

Participants' information on age, height, weight was obtained through a survey. Participants were asked to complete 2 questionnaires, the KCAT and the Updated KCAT. The dietary intake of calcium and vitamin $D$ for the past 1 year was assessed.

Based on the KNHANES VI and VII (2013-2018), food sources of calcium and vitamin D in original KCAT were modified. [15-20] Regarding calcium sources, shrimp, crab, pollack, croaker, skate ray, chili pepper, green pumpkin, chives, perilla leaf, and sea algae were included, but Korean pancake, nuts, bone soup, clam, various fruits, vegetables, and ramen were excluded in the Updated KCAT (Table 1). Regarding vitamin D sources, duck, cow liver, trout, flatfish, salmon, mackerel, herring, saury, and cutlassfish were included, but excluded in the Updated KCAT (Table 1).[7] Calcium and vitamin $D$ contents for the selected foods were obtained from the National Standard Food Composition Tables DB 9.2 and KDRI.[7,21]

\section{Statistical analysis}

All analyses were performed using SPSS version 26.0 (SPSS Inc., Chicago, IL, USA), and $P$-values of less than 0.05 were

Table 1. List of food items newly included in the Updated KCAT

\begin{tabular}{|c|c|c|c|c|c|}
\hline Nutrient & $\begin{array}{l}\text { Food } \\
\text { group }\end{array}$ & Food item & $\begin{array}{l}\text { Serving } \\
\text { size }\end{array}$ & KCAT & $\begin{array}{c}\text { Updated } \\
\text { KCAT }^{\mathrm{a}}\end{array}$ \\
\hline \multirow[t]{10}{*}{ Calcium } & \multirow[t]{2}{*}{ Shellfish } & Shrimp & 1 cup $^{\mathrm{b})}$ & - & $59.2 \mathrm{~g}$ \\
\hline & & Crab & 1 crab & - & $114.0 \mathrm{~g}$ \\
\hline & \multirow[t]{3}{*}{ Fish } & Pollack & 1 serving $^{\mathrm{c})}$ & $18.0 \mathrm{~g}$ & $28.8 \mathrm{~g}$ \\
\hline & & Croaker & 1 serving & $18.0 \mathrm{~g}$ & $105.0 \mathrm{~g}$ \\
\hline & & Skate ray & 1 serving & $18.0 \mathrm{~g}$ & $183.0 \mathrm{~g}$ \\
\hline & \multirow[t]{5}{*}{ Vegetable } & Chili pepper & 1 cup & - & $9.3 \mathrm{~g}$ \\
\hline & & Green pumpkin & 1 cup & - & $22.2 \mathrm{~g}$ \\
\hline & & Chives & 1 cup & - & $22.2 \mathrm{~g}$ \\
\hline & & Perilla leaf & 1 cup & - & $147.7 \mathrm{~g}$ \\
\hline & & Sea algae & 1 cup & - & $81.4 \mathrm{~g}$ \\
\hline \multirow[t]{11}{*}{ Vitamin D } & \multirow[t]{2}{*}{ Meat } & Duck & 1 serving & - & $36.9 \mu \mathrm{g}$ \\
\hline & & Cow liver & 1 piece & - & $0.1 \mu \mathrm{g}$ \\
\hline & \multirow[t]{7}{*}{ Fish } & Trout & 1 serving & $5.0 \mu \mathrm{g}$ & $6.0 \mu \mathrm{g}$ \\
\hline & & Flatfish & 1 serving & $5.0 \mu \mathrm{g}$ & $10.8 \mu \mathrm{g}$ \\
\hline & & Salmon & 1 serving & $5.0 \mu \mathrm{g}$ & $19.2 \mu g$ \\
\hline & & Mackerel & 1 serving & $5.0 \mu \mathrm{g}$ & $6.6 \mu \mathrm{g}$ \\
\hline & & Herring & 1 serving & $5.0 \mu \mathrm{g}$ & $13.2 \mu \mathrm{g}$ \\
\hline & & Saury & 1 serving & $5.0 \mu g$ & $11.4 \mu \mathrm{g}$ \\
\hline & & Cutlass fish & 1 serving & $5.0 \mu \mathrm{g}$ & $8.4 \mu g$ \\
\hline & \multirow[t]{2}{*}{$\begin{array}{l}\text { Mush- } \\
\text { rooms }\end{array}$} & Juda's ear & 1 cup & $19.0 \mu \mathrm{g}$ & $27.3 \mu \mathrm{g}$ \\
\hline & & Mushrooms & 1 cup & $2.0 \mu \mathrm{g}$ & $0.9 \mu \mathrm{g}$ \\
\hline
\end{tabular}

a)Based on National Standard Food Composition Tables DB 9.2.

b) 1 cup $=180 \mathrm{~mL}$.

c) 1 serving $=60 \mathrm{~g}$.

KCAT, Korean Calcium Assessment Tool. 
regarded as statistically significant. The differences of calcium and vitamin $D$ intake between the 2 questionnaires were analyzed by paired $t$-tests. Spearman correlation coefficients were obtained from both questionnaires to compare calcium and vitamin D intake. Cohen's $\mathrm{k}$ coefficient was evaluated to verify the agreement between the 2 questionnaires.[22] The values were interpreted as follows: $<0$, no agreement with the methods; 0 to $0 \cdot 20$, slight agreement; 0.21 to 0.40 , fair agreement; 0.41 to 0.60 , moderate agreement; 0.61 to 0.80 , substantial agreement; and 0.81 to 1.00 , almost perfect agreement.[23] The Bland-Altman plots with 95\% limits of agreement were calculated to visualize the mean differences of agreement between the KCAT and the Updated KCAT for calcium intake and vitamin D intake.[24]

The adequacy of the sample size was determined by the G*Power version 3.1 (Heinrich Heine University, Düsseldorf, Germany).[25] Based on the results of the previous study, [14] a sample size of 275 participants was calculated with a statistical power of $80 \%$ and a level of significance of $5 \%$, and taking a 5\% drop-out rate and incomplete survey, the study planned to enroll 289 participants.

\section{RESULTS}

Calcium intake calculated from the KCAT and the Updated KCAT were not significantly different, but vitamin D intake calculated from the Updated KCAT was significantly higher than that calculated from the KCAT (Table 2). Spearman correlation coefficient test showed that there was a

Table 2. Characteristics of participants and intake of calcium and vitamin D assessed by the KCAT and the Updated KCAT

\begin{tabular}{lccc}
\hline & Total $(\mathrm{N}=285)$ & Range & $P$-value \\
\hline Age $(\mathrm{yr})$ & $35.28 \pm 12.71$ & $19-84$ & \\
Weight $(\mathrm{kg})$ & $56.03 \pm 7.89$ & $42-85$ & \\
Height $(\mathrm{cm})$ & $161.26 \pm 6.06$ & $138-176$ & \\
Body mass index $\left(\mathrm{kg} / \mathrm{m}^{2}\right)$ & $21.56 \pm 2.89$ & $15.43-31.60$ & \\
Calcium (mg/day) & & & 0.343 \\
$\quad$ KCAT & $566.58 \pm 245.72$ & $154.33-1572.10$ & \\
$\quad$ Updated KCAT & $569.12 \pm 248.85$ & $160.94-1547.31$ & \\
Vitamin D ( $\mu \mathrm{g} /$ day) & & & $<0.001$ \\
$\quad$ KCAT & $7.87 \pm 5.40$ & $0.93-31.50$ & \\
Updated KCAT & $10.14 \pm 8.46$ & $0.55-67.28$ & \\
\hline
\end{tabular}

The data is presented as mean \pm standard deviation.

a)Paired $t$-test used for statistical difference on intake of calcium and vitamin D between the KCAT and the Updated KCAT.

KCAT, Korean Calcium Assessment Tool. significant positive correlation between the intake of calcium and vitamin D calculated from the KCAT and the Updated KCAT (Fig. 1). The extent of misclassification by the 2 questionnaires was assessed, and Cohen's K coefficient of 0.95 indicated that the Updated KCAT was able to correctly classify participants into the same quartile of calcium intake, with no participants being grossly misclassified (Table 3). Gross classification according to the quartiles of vitamin D intake also showed moderate agreement between the 2 questionnaires (Table 4). The Bland-Altman plot showed that the mean differences between the KCAT and the Updated KCAT were 2.54 with $95 \%$ limits of agreement between -51.99 to $57.07 \mathrm{mg} /$ day for calcium and 14.28 with
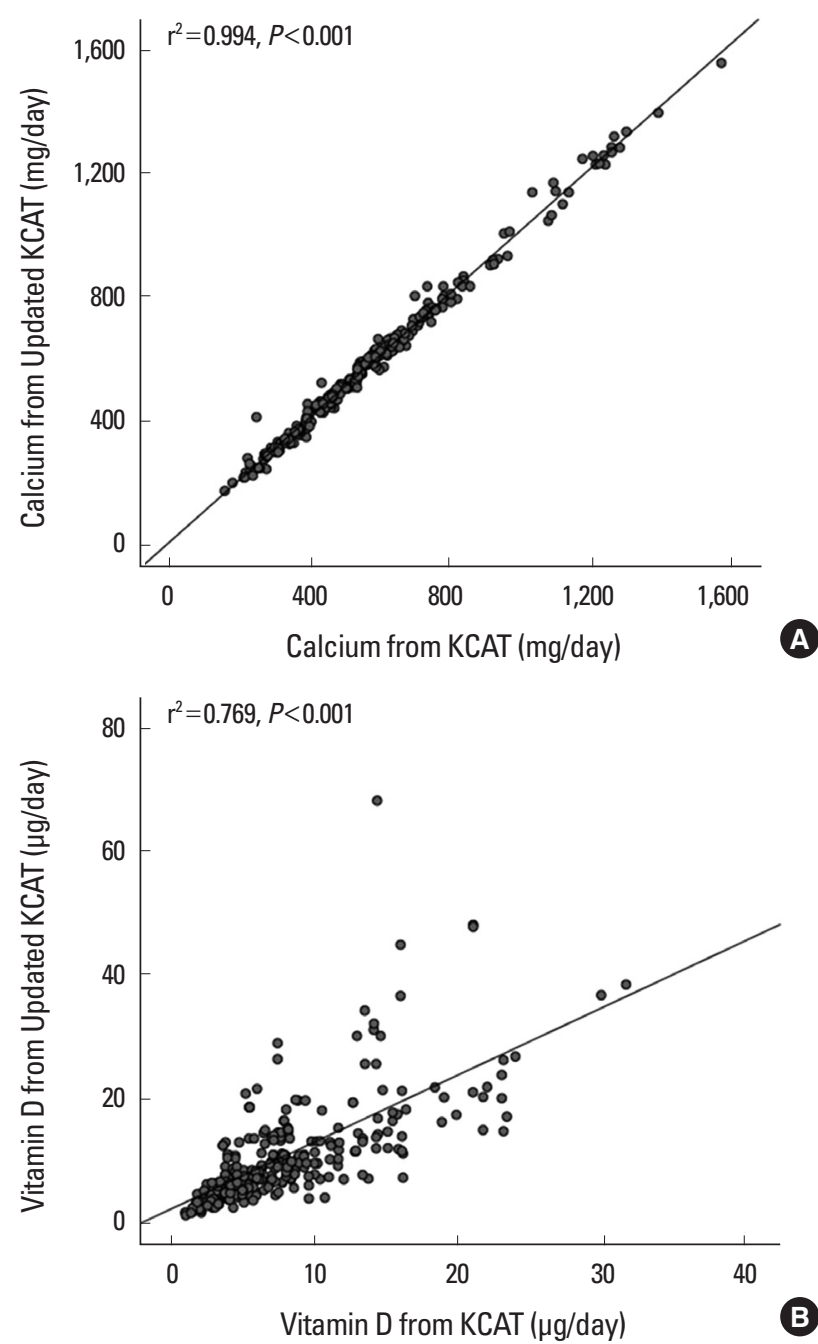

Fig. 1. Correlation of calcium intake (A) and vitamin $D$ intake (B) assessed by the Korean Calcium Assessment Tool (KCAT) and the Updated KCAT 
Table 3. Joint classification of calcium intake assessed of participants according to quartile by the KCAT and the Updated KCAT

\begin{tabular}{|c|c|c|c|c|c|}
\hline \multirow{2}{*}{ Calcium intake by KCAT (mg/day) } & \multicolumn{4}{|c|}{ Calcium intake by Updated KCAT (mg/day) } & \multirow{2}{*}{$\begin{array}{c}\text { Cohen's } \kappa \\
\text { coefficient }^{\text {al }}\end{array}$} \\
\hline & $1(\leq 398.84)$ & $2(>398.84$ to $\leq 529.71)$ & $3(>529.71$ to $\leq 657.17)$ & 4 (>657.17 to $\leq 1547.31)$ & \\
\hline $1(\leq 390.46)$ & 0.97 & 0.03 & 0.00 & 0.00 & 0.949 \\
\hline $2(>390.46$ to $\leq 532.25)$ & 0.03 & 0.96 & 0.00 & 0.00 & \\
\hline $3(>532.25$ to $\leq 658.55)$ & 0.00 & 0.02 & 0.96 & 0.04 & \\
\hline $4(>658.55$ to $\leq 1572.10)$ & 0.00 & 0.00 & 0.04 & 0.96 & \\
\hline
\end{tabular}

${ }^{a}$ Cohen's $\kappa$ coefficient of $0.81-1$ indicates almost perfect agreement.

KCAT, Korean Calcium Assessment Tool.

Table 4. Joint classification of vitamin D intake assessed of participants according to quartile by the KCAT and the Updated KCAT

\begin{tabular}{|c|c|c|c|c|c|}
\hline \multirow{2}{*}{ Vitamin D intake by KCAT ( $\mu \mathrm{g} /$ day) } & \multicolumn{4}{|c|}{ Vitamin D intake by Updated KCAT ( $\mu \mathrm{g} /$ day) } & \multirow{2}{*}{$\begin{array}{c}\text { Cohen's } \kappa \\
\text { coefficient }^{\text {a }}\end{array}$} \\
\hline & $1(\leq 4.86)$ & $2(>4.86$ to $\leq 7.59)$ & $3(>7.59$ to $\leq 12.90)$ & $4(>12.90$ to $\leq 67.28)$ & \\
\hline $1(\leq 3.95)$ & 0.62 & 0.29 & 0.09 & 0.00 & 0.410 \\
\hline 2 (>3.95 to $\leq 6.36$ ) & 0.31 & 0.40 & 0.17 & 0.13 & \\
\hline $3(>6.36$ to $\leq 9.99)$ & 0.06 & 0.23 & 0.46 & 0.25 & \\
\hline $4(>9.99$ to $\leq 31.5)$ & 0.01 & 0.08 & 0.29 & 0.62 & \\
\hline
\end{tabular}

${ }^{a}$ Cohen's $\kappa$ coefficient of 0.41-0.60 indicates moderate agreement.

KCAT, Korean Calcium Assessment Tool.
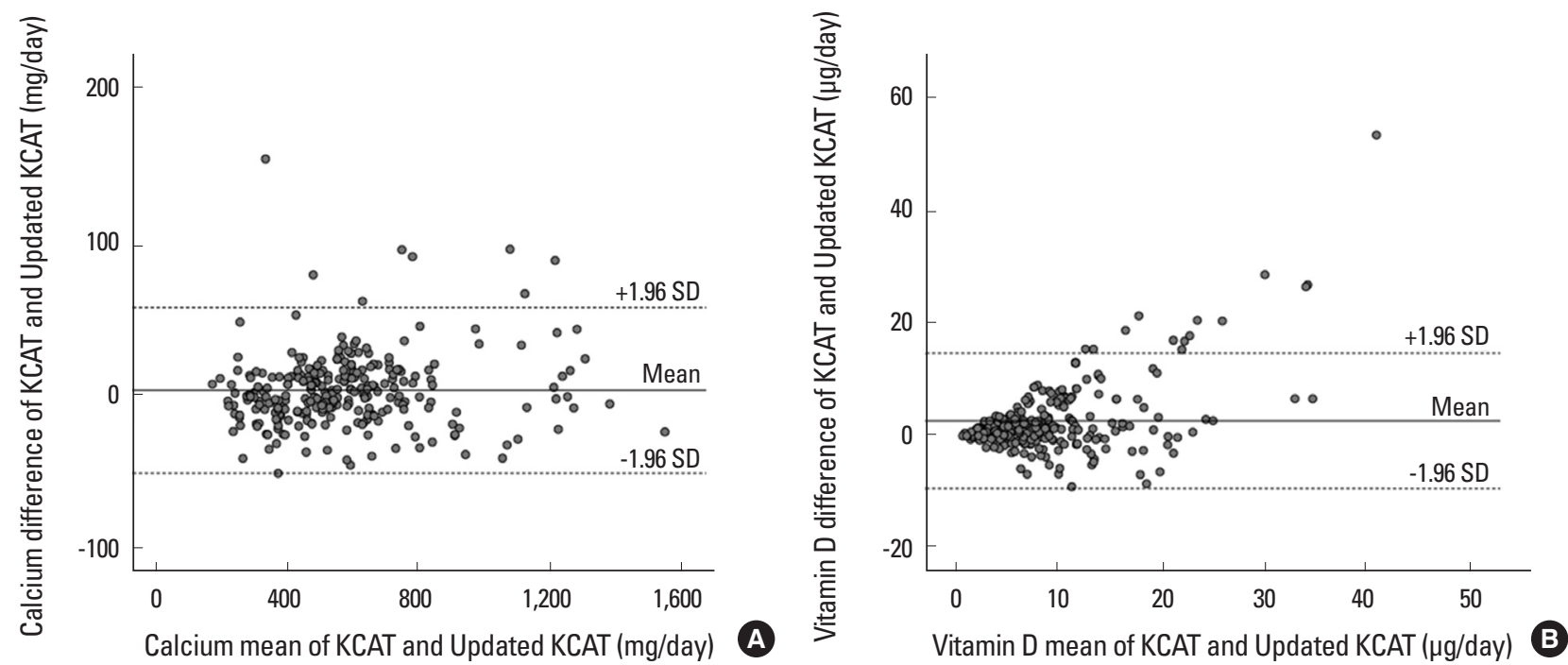

Fig. 2. Differences against mean of calcium intake (A) and vitamin $D$ intake (B) between the Korean Calcium Assessment Tool (KCAT) and the Updated KCAT.

limits of agreement between -9.73 to $14.28 \mu \mathrm{g} /$ day for vitamin D (Fig. 2).

\section{DISCUSSION}

The present study showed that intakes of calcium and vitamin D assessed by the KCAT and the Updated KCAT were positively correlated and correctly classified participants into the same quartile of intake, suggesting that the Updated KCAT was a valid tool to assess the calcium intake of Korean women. In the present study, the correlation coefficient for which using continuous variables of calcium intake estimated by the KCAT and the Updated KCAT was 0.99 , and $\mathrm{k}$ coefficient for which using categorical variables was 0.95 , almost perfect agreement. In the previous studies, the correlation coefficients obtained from calcium in- 
take to validate questionnaires were in the range of 0.41 to 0.98.[14,26-34] Correlation coefficients were 0.51 to 0.98 in Asian populations,[14,28-33] and 0.64 to 0.90 in the western population.[26,27,33,34] Generally, the correlation coefficients for calcium questionnaires were higher with narrow ranges in studies done in Americans and Europeans than in studies done in Asian. These differences could be partly due to the difference of calcium sources. In western population, their calcium sources were simple. Their calcium sources are mostly dependence on milk and milk products, while Asians including Koreans were more varied than the Westerners. Their calcium sources include dark green vegetables, seaweed, beans, and seafood.[35,36] Calcium in dairy products has high bioavailability and is more easily absorbed in the intestine than calcium from nondairy products.[37,38] However, large servings of nondairy products such as dark green vegetables, seaweed, beans, and seafood could also be an important sources of calcium, especially for Koreans.[11] In the present study, Bland-Altman plot also showed good agreement between the KCAT and the Updated KCAT, and calcium estimated by the Updated KCAT was $2.54 \mathrm{mg} /$ day higher than those estimated by the KCAT. This difference could be due to the newly added foods containing high amount of calcium such as crab, croaker, perilla leaf, and sea algae. Calcium intake estimated by the Updated KCAT was $569 \mathrm{mg} /$ day, which was in the range of 513 to $586 \mathrm{mg} /$ day in the urban areas reported by the KNHANES.[39-42] Since KDRI recommends a daily calcium intake of 700 to $800 \mathrm{mg}$ for Korean women,[7] calcium intake is only $71 \%$ to $81 \%$ of recommended level.

In the present study, correlation coefficients of vitamin D intake between the KCAT and the Updated KCAT were 0.77 . This value is higher than the desirable value which is 0.5 and it suggests that the Updated KCAT could be a good tool to assess the intake of vitamin D.[36] Previous studies reported that the correlation coefficients assessed vitamin $D$ intake were in the range of 0.56 to $0.75 .[14,26]$ However, vitamin D intake assessed by the Updated KCAT was higher than that assessed by the KCAT (10.14 $\mu \mathrm{g} /$ day vs. $7.87 \mu \mathrm{g} /$ day) in the present study. This difference could be explained by the newly added food sources high in vitamin $D$, such as duck, cow liver, and fishes, which were included in newly reported the National Standard Food Composition Tables DB 9.2. The average intake fish of the participants was 4.5 $\mu \mathrm{g} /$ day. Fish and mushrooms are an important food source of vitamin D. The intake of fish and shellfish has been increasing 100\% from 2012 to 2017-2019 according to the Korea Rural Economic Institute [43] and the intake of mushrooms has been increasing 32\% from 2012 to 2017-2019 according to the Korea Health Industry Development Institute.[44] The reason for the increased vitamin $D$ intake between 2 questionnaires could be due to the updated food containing vitamin $\mathrm{D}$ (Table 1). Therefore, it is possible that the KCAT underestimated the vitamin D intake, also our results suggested using the Updated KCAT. However, intake of vitamin D in Korean women was still lower than the recommended intake of vitamin $D, 10$ to $15 \mu \mathrm{g} /$ day according to KDRI.[7]

There were a few potential weaknesses in this study. First, FFQ used in these questionnaires was not a quantitative tool to analysis food consumption. To overcome this limitation, FFQ needs to include detailed questions including visual aids for estimating portion sizes. Second, the Updated KCAT might have some reporting bias since self-reported dietary intake data was used. Third, the intake of calcium and vitamin $D$ could be affected by seasonal variation, but the Updated KCAT was not assessed during all 4 seasons. Forth, since participants of the study were only recruited from Seoul, selection bias might be existed. Fifth, the exclusion criteria of participants were different to the previous study that validated original version of KCAT.

The Updated KCAT has a few strengths. First, the Updated KCAT is the only available survey tool to assess dietary intake of calcium and vitamin D for Korean population. Second, the Updated KCAT is simple, convenient, and easy to estimate intake of calcium and vitamin D since it can be completed within 10 to $15 \mathrm{~min}$. Third, the dietary intake of calcium and vitamin $\mathrm{D}$ can be assessed with good validity and reproducibility. In conclusion, this study suggests that the Updated KCAT can be a useful clinical tool for the rapid evaluation of calcium and vitamin D intake for Korean women. The further study is needed to validate the Updated KCAT for other population.

\section{DECLARATIONS}

\section{Acknowledgments}

The authors are grateful to the participants for their involvement in this study. 


\section{Funding}

This work was supported by a National Research Foundation of Korea (NRF) grant funded by the Korea government (MSIT) (NRF-2021R1A2B5B02002208).

\section{Authors' contributions}

JW conducted the study, performed the statistical analysis, and wrote the first draft. YJ revised the manuscript. YP designed the study, finalized the manuscript, and was responsible for the work. All authors have read and agreed to the published version of the manuscript.

\section{Ethics approval and consent to participate}

The study protocol conformed to the ethical guidelines of the World Medical Association Declaration of Helsinki and was approved by the Institutional Review Board (IRB) of Hanyang University (HYUIRB-202103-021). Informed consent were obtained from all participants.

\section{Conflict of interest}

No potential conflict of interest relevant to this article was reported.

\section{ORCID}

Joowon Jin https://orcid.org/0000-0002-7448-8649

Yunjung Lee https://orcid.org/0000-0001-9878-3872

Yongsoon Park https://orcid.org/0000-0001-5110-5716

\section{REFERENCES}

1. Rodrigo L, editor. Osteoporosis: Recent advances, new perspectives and applications. London, UK: IntechOpen; 2021.

2. Ministry of Health \& Welfare and Family Affairs, Korea Center for Disease Control and Prevention. Korea health statistics 2008: Korea national health and nutrition examination survey (KNHANES IV-2). Seoul: Korea Center for Disease Control and Prevention; 2009.

3. Delaney MF. Strategies for the prevention and treatment of osteoporosis during early postmenopause. Am J Obstet Gynecol 2006;194:S12-23. https://doi.org/10.1016/j.ajog. 2005.08.049.

4. Jackson RD, LaCroix AZ, Gass M, et al. Calcium plus vitamin D supplementation and the risk of fractures. N Engl J Med 2006;354:669-83. https://doi.org/10.1056/NEJMoa055218.
5. Rizzoli R, Boonen S, Brandi ML, et al. The role of calcium and vitamin $\mathrm{D}$ in the management of osteoporosis. Bone 2008;42:246-9. https://doi.org/10.1016/j.bone.2007.10.005.

6. Love $C$. Dietary needs for bone health and the prevention of osteoporosis. Br J Nurs 2003;12:12-21. https://doi.org/ 10.12968/bjon.2003.12.1.10994.

7. Ministry of Health and Welfare, The Korean Nutrition Society. Dietary reference intakes for Koreans 2015. Sejong: Ministry of Health and Welfare; 2015.

8. Lanham-New SA. Importance of calcium, vitamin D and vitamin $\mathrm{K}$ for osteoporosis prevention and treatment. Proc Nutr Soc 2008;67:163-76. https://doi.org/10.1017/s0029 665108007003.

9. BC Dairy Association. Calcium calculator ${ }^{\mathrm{TM}}$. 2021 [cited by $2021 \mathrm{Jul}$ 26]. Available from: https://bcdairy.ca/calciumcalculator/

10. Hung A, Hamidi M, Riazantseva E, et al. Validation of a calcium assessment tool in postmenopausal Canadian women. Maturitas 2011;69:168-72. https://doi.org/10.1016/ j.maturitas.2011.02.016.

11. Park HM, Heo J, Park Y. Calcium from plant sources is beneficial to lowering the risk of osteoporosis in postmenopausal Korean women. Nutr Res 2011;31:27-32. https:// doi.org/10.1016/j.nutres.2010.12.005.

12. Weaver CM, Plawecki KL. Dietary calcium: adequacy of a vegetarian diet. Am J Clin Nutr 1994;59:1238s-41s. https:// doi.org/10.1093/ajcn/59.5.12385.

13. Weaver CM. Calcium bioavailability and its relation to osteoporosis. Proc Soc Exp Biol Med 1992;200:157-60. https: //doi.org/10.3181/00379727-200-43409.

14. Park Y, Kim SH, Lim YT, et al. Validation of a new food frequency questionnaire for assessment of calcium and vitamin d intake in korean women. J Bone Metab 2013;20:6774. https://doi.org/10.11005/jbm.2013.20.2.67.

15. Ministry of Health \& Welfare, Korea Centers for Disease Control and Prevention. Korea health statistics 2013: Korea national health and nutrition examination survey (KNHANES VI-1). Sejong: Korea Center for Disease Control and Prevention; 2014.

16. Ministry of Health \& Welfare, Korea Centers for Disease Control and Prevention. Korea health statistics 2014: Korea national health and nutrition examination survey (KNHANES VI-2). Sejong: Korea Center for Disease Control and Prevention; 2015.

17. Ministry of Health and Welfare, Korea Disease Control and 
Prevention. Korea health statistics 2015: Korea national health and nutrition examination survey (KNHANES VI-3). Sejong: Korea Center for Disease Control and Prevention; 2016.

18. Ministry of Health and Welfare, Korea Centers for Disease Control and Prevention. Korea health statistics 2016: Korea national health and nutrition examination survey (KNHANES VII-1). Sejong: Korea Centers for Disease Control and Prevention; 2017.

19. Ministry of Health and Welfare, Korea Disease Control and Prevention Agency. Korea health statistics 2017: Korea national health and nutrition examination survey (KNHANES VII-2). Sejong: Korea Center for Disease Control and Prevention; 2018.

20. Ministry of Health and Welfare, Korea Disease Control and Prevention. Korea health statistics 2018: Korea national health and nutrition examination survey (KNHANES VII-3). Sejong: Korea Centers for Disease Control and Prevention; 2019.

21. National Institute of Agricultural Sciences. Korean food composition Table DB 9.2. 2021 [cited by 2021 Oct 11]. Available from: http://koreanfood.rda.go.kr/kfi/fct/fctlntro/list?menuld = PS03562\#

22. Taylor R. Interpretation of the correlation coefficient: a basic review. J Diagn Med Sonogr 1990;6:35-9.

23. Cohen J. Weighted kappa: nominal scale agreement with provision for scaled disagreement or partial credit. Psychol Bull 1968;70:213-20. https://doi.org/10.1037/h0026256.

24. Altman DG, Bland JM. Measurement in medicine: the analysis of method comparison studies. J R Stat Soc Series B Statistician 1983;32:307-17.

25. Faul F, Erdfelder E, Lang AG, et al. G*Power 3: a flexible statistical power analysis program for the social, behavioral, and biomedical sciences. Behav Res Methods 2007;39:17591. https://doi.org/10.3758/bf03193146.

26. Itkonen ST, Erkkola M, Skaffari E, et al. Development and validation of an interview-administered FFQ for assessment of vitamin D and calcium intakes in Finnish women. $\mathrm{Br} J$ Nutr 2016;115:1100-7. https://doi.org/10.1017/s000711 4515005474.

27. Montomoli M, Gonnelli S, Giacchi M, et al. Validation of a food frequency questionnaire for nutritional calcium intake assessment in Italian women. Eur J Clin Nutr 2002;56: 21-30. https://doi.org/10.1038/sj.ejcn.1601278.

28. Chee WS, Suriah AR, Zaitun Y, et al. Dietary calcium intake in postmenopausal Malaysian women: comparison between the food frequency questionnaire and three-day food records. Asia Pac J Clin Nutr 2002;11:142-6. https:// doi.org/10.1046/j.1440-6047.2002.00276.x.

29. Osowski JM, Beare T, Specker B. Validation of a food frequency questionnaire for assessment of calcium and bonerelated nutrient intake in rural populations. J Am Diet Assoc 2007;107:1349-55. https://doi.org/10.1016/j.jada.2007. 05.012.

30. Uenishi K, Ishida H, Nakamura K. Development of a simple food frequency questionnaire to estimate intakes of calcium and other nutrients for the prevention and management of osteoporosis. J Nutr Sci Vitaminol (Tokyo) 2008; 54:25-9. https://doi.org/10.3177/jnsv.54.25.

31. Khan NC, Mai le B, Hien VT, et al. Development and validation of food frequency questionnaire to assess calcium intake in postmenopausal Vietnamese women. J Nutr Sci Vitaminol (Tokyo) 2008;54:124-9. https://doi.org/10.3177/ jnsv.54.124.

32. Xu L, Porteous JE, Phillips MR, et al. Development and validation of a calcium intake questionnaire for postmenopausal women in China. Ann Epidemiol 2000;10:169-75. https://doi.org/10.1016/s1047-2797(99)00055-1.

33. Severo M, Lopes $C$, Lucas $R$, et al. Development of a tool for the assessment of calcium and vitamin D intakes in clinical settings. Osteoporos Int 2009;20:231-7. https:// doi.org/10.1007/s00198-008-0647-6.

34. Magkos F, Manios Y, Babaroutsi E, et al. Development and validation of a food frequency questionnaire for assessing dietary calcium intake in the general population. Osteoporos Int 2006;17:304-12. https://doi.org/10.1007/s00198004-1679-1.

35. Bhavadharini B, Dehghan M, Mente A, et al. Association of dairy consumption with metabolic syndrome, hypertension and diabetes in 147812 individuals from 21 countries. BMJ Open Diabetes Res Care 2020;8:e000826. https://doi. org/10.1136/bmjdrc-2019-000826.

36. Wang Y, Li S. Worldwide trends in dairy production and consumption and calcium intake: is promoting consumption of dairy products a sustainable solution for inadequate calcium intake? Food Nutr Bull 2008;29:172-85. https:// doi.org/10.1177/156482650802900303.

37. Adolphi B, Scholz-Ahrens KE, de Vrese M, et al. Short-term effect of bedtime consumption of fermented milk supplemented with calcium, inulin-type fructans and caseinpho- 
sphopeptides on bone metabolism in healthy, postmenopausal women. Eur J Nutr 2009;48:45-53. https://doi.org/ 10.1007/s00394-008-0759-y.

38. Varenna M, Binelli L, Casari S, et al. Effects of dietary calcium intake on body weight and prevalence of osteoporosis in early postmenopausal women. Am J Clin Nutr 2007; 86:639-44. https://doi.org/10.1093/ajcn/86.3.639.

39. Hong MH, Oh SY. Within-and between-person variation in nutrient intakes by the Korean elderly. Korean J Community Nutr 1998;3:423-9.

40. Kim SY, Jung K, Lee B, et al. A study of the dietary intake status and one portion size of commonly consumed food and dishes in Korean elderly women. Korean J Community Nutr 1997;2:578-92.
41. Lee HS, Chang MJ. Effect of family type on the nutrient intake and nutritional status in elderly women. J Korean Soc Food Sci Nutr 1999;28:934-41.

42. Kim SW, Bae KH, Seo JB, et al. Association between household size, residential area, and osteoporosis: analysis of 2008 to 2011 Korea National Health and Nutrition Examination Survey. Korean J Intern Med 2016;31:712-21. https: //doi.org/10.3904/kjim.2015.274.

43. Korea Rural Economic Institute. 2019 Food balance sheet Naju: Korea Rural Economic Institute; 2020.

44. Korea Health Industry Development Institute. National food and nutrition statistics. 2020 [cited by 2021 Oct 11]. Available from: https://www.khidi.or.kr/nutristat?year=2 019\&menuld $=$ MENU01649 